\title{
Awareness and Attitude of Women Towards their Spouse's use of Vasectomy as a Fertility Control Method in Jos, North-Central Nigeria
}

\author{
*UTOO, B.T and **UTOO, PM
}

\begin{abstract}
*Department of Obstetrics \& Gynaecology, Jos University Teaching Hospital
**Department of community health \& Epidemiology College of health sciences, Benue State University Makurdi
\end{abstract}

Correspondenceto: Dr Utoo, B. Terkimbi

Department of Obstetrics \& Gynaecology, Jos University Teaching Hospital, P.O BOX 10480, University of Jos.

Email:bernardutoo@yahoo.com

\begin{abstract}
Background: Vasectomy, though a safe, simple outpatient surgical procedure for male sterilization, it is the least used in developing countries of the world. This study was set to determine the awareness and attitude of women towards their spouse's use of vasectomy for fertility control.

Method: This was a cross-sectional study involving 400 women who attended antenatal clinic at the Jos University Teaching Hospital (JUTH), Jos, Nigeria from September 2007 to march 2008.

Results: Among the 400 respondents only 98(24.5\%) were aware of vasectomy. The commonest source of information was from health workers in the hospital (47.96\%). Most of the women 359(89.75\%) approved of male contraception with only 41(10.25\%) disapproving. However, 81.25\% disapproved with the use of vasectomy by their spouses. Most of those who disapproved of vasectomy gave their reasons as fear of sexual dysfunction (43.10\%), religious prohibition (24.62\%), cultural prohibition (19.05\%), future regrets (9.85\%) and fear of marital infidelity by their spouse (3.38\%). More Christians (80.74\%) approved for spouse to use vasectomy than Muslims (17.30\%). The educated women (82.96\%) were more willing to allow their spouse use vasectomy than the uneducated (33.33\%).

Conclusion: The awareness of vasectomy was low. Although most women approved of male contraception for fertility control, they would not allow their spouse to use vasectomy. More targeted efforts by promoting women education, economic empowerment, family planning enlightenment programmes as well as the involvement of traditional and religious leaders should be made to improve awareness and acceptability of vasectomy by both men and women in developing countries.
\end{abstract}

Key Words: Awareness, Attitude, Male contraception, Vasectomy, Fertility control.

\section{Introduction}

Despite currently available contraceptives, the world population exceeds 6.5billion and is increasing by 75 million yearly ${ }^{1}$.Overpopulation continues to be a significant contributor to environmental degradation and human suffering worldwide ${ }^{1}$.Much of our current global population growth is unintended. It is estimated that half of all conceptions are unplanned and half of the resulting pregnancies are undesired $^{1,2}$.

Research and family planning organizations have traditionally focused upon female methods of contraception because women bear a disproportionate portion of the health and economic consequences of child bearing and rearing ${ }^{3}$.However the appeal of a male contraceptive to both men and women is a welcome development. In surveys spanning four continents, a majority of men indicated a willingness to use a male contraceptive if one were available . $^{3-5}$.

There are few available options for male contraceptive methods. This includes; hormonal based contraceptives, withdrawal, condoms and vasectomy. The last two been the most commonly practiced methods. Despite few available options, male methods account for approximately $14 \%$ of contraception worldwide, with prevalence significantly higher in the developed world where male directed methods account for more than 30\% of contraception ${ }^{3}$.

Vasectomy is a safe, simple outpatient surgical procedure done under local anesthesia for male sterilization. In this procedure, the ductus deference is severed and the ends ligated through a small scrotal incision ${ }^{7,8}$. Approximately 500,000 
vasectomies are performed yearly in the united states $^{6}$, where approximately $10 \%$ of couples using contraception rely on this method. Worldwide, over 40million men have undergone the procedure accounting for $5 \%$ of active contraception ${ }^{7}$.Failure rate is less than $1 \%$ with a low incidence of complications ${ }^{6}$.

Vasectomy is least used in developing countries of the world. In northern Nigeria, it is considered to be a neglected method of permanent contraception ${ }^{8}$.An earlier study carried out in Jos showed an acceptability rate of the method to be $0.28 \%{ }^{8}$. Some health care providers are prejudiced against vasectomy because of lingering misconceptions about the effect of the method on health and sexual function and hence underestimate the demand of males for vasectomy ${ }^{8}$. In a nation-wide survey in Nigeria, more than twofifths $(43 \%)$ of respondents expressed the opinion that decisions on the use of family planning methods be jointly taken by couples ${ }^{9}$.It is based on this background information that this study was set to determine the awareness and attitude of women towards their spouse's use of vasectomy as a method of fertility control.

\section{Subjects and Methods}

This was a cross sectional study involving 400 antenatal clinic attendees at the Jos University Teaching Hospital. The hospital is a 500 bed tertiary health center in north-central Nigeria and serves as a referral center for private, cottage, general and specialist hospitals in this region of the country. Data collection was through a structured pre-tested interviewer administered questionnaire. Women who attended the clinic between September 2007 to march 2008 and consented to be part of the study were recruited. Information obtained included: age, occupation, educational status, ethnicity, religion, parity, awareness and attitude towards male sterilization (vasectomy).The data was analyzed using EPI info version 3.2.2.The data was presented in a tabular format and compared using simple percentages. Chi Square was used as test of statistics with $\mathrm{P}$ value of less than 0.05 considered statistically significant.

\section{Results}

Four hundred respondents were interviewed out of which $37.5 \%$ were aged between $25-29$ years. One percent were 19 years or less while $0.8 \%$ were 40 years and above. Forty two $(10.5 \%)$ of the women did not have any formal education. Sixteen percent had primary, $34.75 \%$ had secondary and $38.75 \%$ had tertiary level of education. Twenty-seven point eight percent were housewives. Majority (74\%) of respondents were Christians while 26\% were Muslims. The beroms constituted 20.5\%, Hausa $15.7 \%$, Ibos $12.7 \%$ among the diverse ethnic groups studied (Table I). Most of the respondents (61.5\%) had 1-2 living children. Only 5\% had 4 or more living children (Table II). Eighty nine point seven five percent of the respondents accepted that men should use contraceptive methods (Figure 1). However, only twenty four point five percent were aware of vasectomy and the commonest source of information was from health workers in the hospital $(47.96 \%)$ Table III. As high as $81.25 \%$ disapproved with the use of vasectomy by spouse for fertility control (Figure 2). Among those who refused for spouse to use vasectomy gave reasons of; fear of sexual dysfunction $43.10 \%$, religious prohibition $24.62 \%$, cultural prohibition $19.05 \%$ and fear of marital infidelity $3.38 \%$ (TableIV). There was a statistically significant relationship $(p<0.05)$ between religion, educational status and the approval for the use of vasectomy. More Christians $(80.74 \%)$ approved of the use of vasectomy than Muslims (17.30\%). The educated women $(82.96 \%)$ were more willing to allow their spouses use vasectomy than the uneducated $(33.33 \%)$ (Table V).

\section{Discussion}

Several studies have demonstrated that male contraceptive is becoming appealing to both males and females. In this study, $89.75 \%$ of women approved for spouse to use contraceptive. This is similar to a study done in the United States of America (USA) where 98\% of women in stable relationship were willing to rely on their male partners to use male contraceptive ${ }^{6}$. This high level of acceptability of male contraceptives may be due to the fact that most women in this study had at least primary level of education $(89.50 \%)$ ).It has been shown that the educated women are more likely to accept family planning method.

Although majority of the women approved of the use of male contraceptive by their spouses, their attitude towards vasectomy was however different. Eighty one point twenty five percent of the respondent disapproved with the use of vasectomy by their spouses. This finding could portend a major setback to the use of vasectomy by men for fertility control since majority of women had opined that family planning decision should be jointly taken by couples and not one partner ${ }^{10}$. 
Although vasectomy is an acceptable technique of sterilization in affluent societies cultural barriers exist in most parts of Africa. Other factors that have been noted to influence the use of male contraceptive methods generally are namely economy, religion and relationship status of the partners etc. In this study, religion was noted to negatively affect the approval of vasectomy by the women. This is similar to findings of a study done in Sokoto, northern Nigeria where it was observed that the use of family planning methods for birth/population control was traditionally considered strictly unislamic and therefore culturally unacceptable ${ }^{12,13}$.

Reasons given by respondents for their disapproval with the use of vasectomy by their spouses included sexual dysfunction, religious prohibition, cultural prohibition, future regrets and fears that their spouses would become promiscuous. Several studies done in Europe and UK did not demonstrate significantly that vasectomy was harmful to the health of men. In a review of 357 vasectomies for male sterilization; it was found out that the clients were psychosexually satisfied with the procedure and would recommend it to friends. The fear of prostate cancer following vasectomy has not also been convincingly demostrated ${ }^{13-16}$.

The findings in this study suggest that the blame for the low acceptability of vasectomy in developing nations may not lie squarely with the men. The attitude of women towards the use of vasectomy by their spouses is equally not encouraging. The strategy for improving this trend should involve more targeted efforts by promoting women education, economic empowerment, information dissemination and enlightenment campaigns by family planning experts. Involvement of religious leaders and traditional rulers in the exercise is also crucial to improving awareness and acceptability of vasectomy in developing countries of the world.

TABLE I: Socio-demographic Characteristics of Respondents $(n=400)$

\begin{tabular}{lll}
\hline Characteristic & $(\mathbf{n = 4 0 0 )}$ & $\mathbf{( \% )}$ \\
\hline Age in years & & \\
$\square 19$ & 4 & 1.0 \\
$20-24$ & 87 & 21.7 \\
$25-29$ & 150 & 37.5 \\
$30-34$ & 117 & 29.2 \\
$35-39$ & 39 & 9.80 \\
$40-44$ & 3 & 0.80
\end{tabular}

\begin{tabular}{lll}
\hline Educational Level & & \\
None & 42 & 0.75 \\
Primary & 64 & 8.00 \\
Secondary & 139 & 36.50 \\
Tertiary & 155 & 54.75 \\
\hline Occupation & & \\
Business & 109 & 27.30 \\
Housewife & 111 & 27.80 \\
Student & 68 & 17.00 \\
Farming & 52 & 13.00 \\
Teaching & 45 & 11.20 \\
Civil servant & 15 & 3.70 \\
\hline Religion & & \\
Christians & 296 & 74.00 \\
Muslims & 104 & 26.00 \\
\hline Ethnic group & & \\
Berom & 82 & 20.50 \\
Hausa & 63 & 15.70 \\
Igbo & 51 & 12.70 \\
Yoruba & 21 & 5.30 \\
Jarawa & 20 & 5.00 \\
Mwaghavul & 35 & 8.80 \\
Others & 128 & 32.00
\end{tabular}

TABLE II: Distribution of living children among the women

\begin{tabular}{lll}
\hline Living Children & $\mathbf{N = 4 0 0}$ & $\mathbf{\%}$ \\
\hline None & 83 & 20.75 \\
$1-2$ & 246 & 61.50 \\
$3-4$ & 51 & 12.75 \\
More than 4 & 20 & 5.00 \\
\hline
\end{tabular}

TABLE III: Awareness and source of awareness of vasectomy by the women

\begin{tabular}{lll}
\hline Awareness & $\mathbf{N = 4 0 0}$ & $\mathbf{\%}$ \\
\hline Yes & 98 & 24.5 \\
No & 302 & 75.5 \\
$\begin{array}{l}\text { Source of } \\
\text { Awareness }\end{array}$ & $\mathbf{N = 9 8}$ & $\mathbf{\%}$ \\
& & \\
Hospital & 47 & 47.96 \\
Mass media & 32 & 32.65 \\
Friends & 15 & 15.31 \\
Others & 4 & 4.08 \\
\hline
\end{tabular}

TABLE IV: Reasons for women's disapproval for spouse to use vasectomy

\begin{tabular}{lll}
\hline Reasons & $\mathbf{N}=\mathbf{3 2 5}$ & $\mathbf{\%}$ \\
\hline $\begin{array}{l}\text { Fear of sexual } \\
\text { dysfunction }\end{array}$ & 140 & 43.10 \\
Religious prohibition & 80 & \\
Cultural prohibition & 62 & 24.62 \\
Future regrets & 32 & 19.05 \\
Fear of marital infidelity & 11 & 9.85 \\
& & 3.38 \\
\hline
\end{tabular}


TABLE V: Approval for vasectomy by religion and educational status

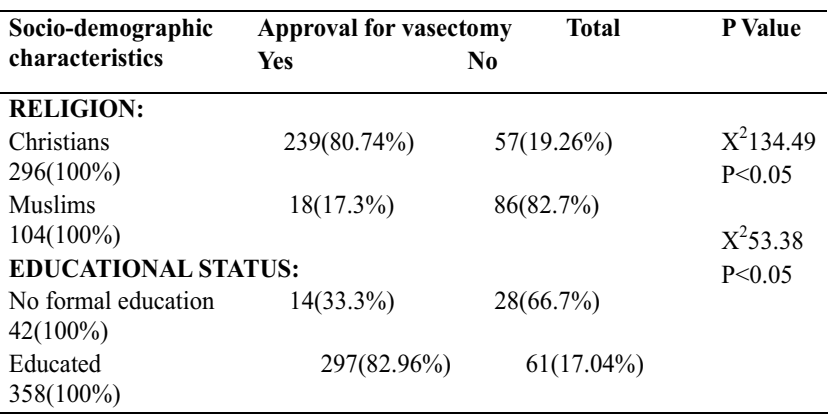

\section{References}

1 Stephanie T P, John K A and William JB. Advances in male contraception. Endocrine Review, 2008; 29(4):465-493.

2 Henshaw S K. Unintended pregnancy in the United States.Fam Plan Perspect, 1998; 30:24-29.

3 Christiana W, Roland S S. Male hormonal contraception. Am J Obstet Gynecol, 2004; 190:60-68.

4 Heinemann K, SaadF, Wiesemes M, White S, Heinemann L.Expectations towards a novel male fertility control method and potential user types: results of a multinational survey Androl, 2005; 26:155-162.

5 Heinemann K, Saad F, wiesemes M, White S, Heinemann L. Attitudes toward male fertility control: results of a multinational survey on four continents. Hum Reprod, 2005; 20:549-556

6 Magnani RJ, Haws JM, Morgan GT, Gargiullo PM, Pollock AE and Koonin LM.Vasectomy in the United States, 1991 and 1995. Am J Pub Health, 1999; 89:9294.
7 Peterson HB, Curtis KM.Clinical practice. Long acting methods of contraception. Engl J Med, 2005; 353:21692175.

8 Mutihir JT, Ujah IAO, Ekwempu CC, Daru PH, and Olabisi AA. Acceptability of vasectomy in Jos, North central Nigeria.Trop J Obstet Gynaecol, 2004; 21(1):56-57.

9 Federal Ministry of Health. National HIV/AIDS and Reproductive Health Survey (NARHS) Abuja, Nigeria, 2003:111-112.

10 Niels-Peter Roland W,Gianfranco M,Brigitta W and Wolf L.Post vasectomy erectile dysfunction. J Psychomatic Research, 1994; 38(7):759-762.

11 Dunmoye OO, Moodley J and Popis M.Vasectomy in developing countries.J Obstet Gynaecol, 2001; 21(3):295-297.

12 Ibrahim MI and Okolo RU.Profile of contraceptive acceptors in UDUTH, Sokoto, Nigeria.Nig Med Pract, 1997; 33(1/2):9-13.

13 Isah AY and Nwobodo EI. Family planning practice in a tertiary health institution in North-Western Nigeria.Nig J Clin Pract, 2009; 12(3):281-283.

14 Tailly G, Vereecken RI, Verduyn H. A review of 357 bilateral vasectomies for male sterilization.Fertil Steril, 1984; 41(3):424-427.

15 Mc Donald SW.Is vasectomy harmful to health? Br J Gen Pract, 1997; 47(419):381-386.

16 Tripathy SP, Ramachandran CR and Ramachandran P.Health consequences of vasectomy in India. Bull world Health, 1994; 72(5):779-782. 